\title{
SISTEM RUJUKAN DALAM SISTEM PELAYANAN KESEHATAN MATERNAL PERINATAL DI INDONESIA
}

\section{REFFERAL SYSTEM IN MATERNAL PERINATAL HEALTH SERVICES IN INDONESIA}

\author{
Luluk Susiloningtyas ${ }^{1}$ \\ 1 STIKes Pamenang \\ *Korespondensi Penulis : luluksusiloningtyas@gmail.com
}

\begin{abstract}
Abstrak
Kasus keterlambatan rujukan merupakan salah satu permasalahan utama terjadinya kematian ibu dan bayi di Indonesia. Kematian ibu dan bayi dapat diakibatkan pelayanan di fasilitas kesehatan belum maksimal, terjadi keterlambatan pelayanan rujukan, mengakibatkan sangat terlambatnya pasien tiba di fasilitas pelayanan rujukan. Berbagai hambatan termasuk ketidakjelasan hubungan dengan BPJS Kesehatan dalam hal pengaturan sistem rujukan, terjadinya perbedaan pendapat rujukan dan perhatian terhadap pengembangan sistem rujukan di daerah yang masih kurang kuat. Tahun 2020 Kementerian Kesehatan RI mengeluarkan Permenkes No. 3/2020 yang mengatur Klasifikasi dan Perizinan Rumah sakit, yang tentunya mempengaruhi sistem rujukan. Dengan sistem rujukan diharapkan meningkatkan pelayanan kesehatan yang lebih bermutu. Metode yang diambil berdasarkan tinjauan literatur dan penelitian yang mencoba menggali lebih banyak informasi guna mengetahui sistem rujukan yang terjadi di Indonesia baik kabupaten, provinsi, puskesmas dan rumah sakit.

Sistem rujukan pelayanan kesehatan merupakan salah satu upaya meningkatkan mutu pelayanan kesehatan yang memberikan dampak penurunan Angka Kematian Ibu dan Bayi akibat keterlambatan penanganan kegawatdaruratan. Sistem rujukan merupakan sistem dimana kordinasi merupakan unsur utama yang bersifat multi sektor dan harus ada dukungan berbagai profesi multi disiplin dan multi profesi. Untuk mendukung hal tersebut seluruh sarana pelayanan kesehatan pemerintah maupun swasta agar melaksanakan prosedur rujukan kesehatan mengacu Petunjuk Teknis Sistem Rujukan Pelayanan Kesehatan. Setiap sarana pelayanan kesehatan di kabupaten/kota diharapkan membuat pemetaan alur rujukan pelayanan kesehatan disesuaikan dengan tingkat kemampuan fasilitas kesehatan, keberadaan jaringan transportasi dan keadaan geografis wilayah masing-masing.

Simpulan penyediaan akses pelayanan kesehatan ibu dan anak yang berkualitas menjadi tantangan besar, pemerintah harus memiliki komitmen kuat meningkatkan status kesehatan ibu dan anak, untuk mewujudkan program penurunan AKI dan AKB tersebut diperlukan perbaikan sistem rujukan yang efektif dan efisien dengan memperkuat sistem rujukan kesehatan diberbagai jenjang pelayanan kesehatan.
\end{abstract}

Kata kunci : Sistem Rujukan, Pelayanan Kesehatan, Maternal Perinatal

\begin{abstract}
Late of referral is one of the main problems in the occurrence of maternal and infant mortality in Indonesia. Maternal and infant deaths can be caused by services at health facilities not yet maximized, there is a delay in referral services, resulting in very late patients arriving at the referral service facility. Various obstacles include unclear relations with BPJS Health in terms of setting a referral system, the occurrence of differences of referral opinions and attention to the $d$ The health service referral system is one of the efforts to improve the quality of health services which has the effect of reducing maternal and infant mortality rates due to delays in emergency handling. The referral system is a system where coordination evelopment of a referral system in regions that are still not strong enough. is the main element that is multi-sectoral and there must be support from various multi-disciplinary and multi-professional professions. To support this,
\end{abstract}

Submitted : 9 Mei 2020, Accepted $\quad$ : 7 Juni 2020

Website : jurnal.stikespamenang.ac.di | Email : jurnal.pamenang@gmail.com 
all public and private health service facilities should carry out health referral procedures referring to the Technical Guidelines for Health Services Referral Systems. Each health service facility in the district / city is expected to make a mapping of health service referral flow tailored to the level of ability of the health facility, the existence of the transportation network and the geographical situation of each region.

Conclusion the provision of access to quality maternal and child health services is a big challenge, the government must have a strong commitment to improve maternal and child health status, to realize the MMR and IMR Reduction program, it is necessary to improve an effective and efficient referral system by strengthening the health referral system at various levels of service health.'

Keywords: Referral System, Health Services, Maternal Perinatal

\section{Pendahuluan}

Salah satu kelemahan pelayanan kesehatan adalah pelaksanaan rujukan yang kurang tepat dan cepat. Kematian ibu dan bayi diakibatkan karena pelayanan di fasilitas kesehatan belum maksimal ataupun terjadi keterlambatan pelayanan rujukan bagi ibu dan bayi yang mengakibatkan sangat terlambat pula pasien tiba di fasilitas pelayanan rujukan (Tirtaningrum, A.D, 2018). Dengan adanya sistem rujukan diharapkan dapat meningkatkan pelayanan kesehatan yang lebih bermutu. Kelancaran rujukan dapat menjadi faktor yang menentukan untuk menurunkan Angka Kematian Ibu (AKI) dan perinatal terutama dalam mengatasi keterlambatan menjadi penyebab peningkatan Angka Kematian Ibu dan Bayi. Di Indonesia sudah sangat dikenal istilah "3 terlambat" yang menjadi penyebab kematian ibu dan bayi yaitu terlambat pengambilan keputusan di tingkat keluarga, terlambat mencapai fasilitas pelayanan kesehatan dan terlambat mendapat pertolongan di tingkat fasilitas kesehatan. Terlambat mengambil keputusan biasanya terjadi karena ibu lebih memilih untuk melahirkan di rumah, adanya kendala biaya atau transportasi, dan permasalahan akses ke fasilitas kesehatan yang tidak terjangkau (geografis). Terlambat yang kedua, terlambat mencapai fasilitas kesehatan ini biasanya terjadi karena adanya masalah transportasi, tidak adanya jejaring rujukan yang formal antara bidan desa dengan rumah sakit, dan tidak adanya protokol rujukan. Terlambat dalam mendapat pertolongan yang memadai di fasilitas kesehatan terjadi karena rendahnya kualitas perawatan obstetri dan neonatus di berbagai fasilitas, adanya persepsi rendahnya pelayanan untuk pasien berasuransi sosial seperti BPJS, dan pemberian rujukan balik yang tidak umum. Dari 3 terlambat tadi jika dikaji lebih lanjut akan kita jumpai adanya masalah dalam sistem rujukan. Oleh sebab itu, diperlukan perbaikan dalam sistem rujukan yang ada sehingga tercapai sistem rujukan yang efektif dan efisien (Tirtaningrum, AD, 2018) .

Pada 2014 telah diterbitkan Keputusan Menteri Kesehatan RI No. HK.02.02/MENKES/390/2014 tentang Pedoman Penetapan Rumah Sakit Rujukan Nasional. Permenkes ini membahas adanya rumah sakit rujukan nasional, rujukan provinsi, dan rujukan regional. Strategi pelaksanaan rumah sakit rujukan pada 2017 dengan melakukan pemetaan rumah sakit rujukan nasional, provinsi, regional dengan penguatan sistem telematika. Pada 2019 terlihat bahwa pengembangan sistem rujukan masih membutuhkan penguatan. Berbagai hambatan terjadi termasuk ketidakjelasan hubungan dengan Badan Penyelenggara Jaminan Sosial (BPJS) Kesehatan dalam hal pengaturan sistem rujukan, terjadinya perbedaan pendapat rujukan berjenjang ataukah rujukan berbasis kompetensi, demikian pula perhatian terhadap pengembangan sistem rujukan di daerah yang masih kurang kuat. Terkait Sistem Rujukan saat ini, Pada tahun 2020 Kementerian Kesehatan RI mengeluarkan Permenkes No. 3/2020 yang mengatur Klasifikasi dan Perizinan Rumah Sakit. Keberadaan Permenkes/PMK 3/2020 tentunya mempengaruhi sistem rujukan. Secara konsepsual PMK No 3/2020 memperkuat pemetaan penjenjangan rujukan berbasis kompetensi penanganan. Sistem rujukan berjenjang berbasis kompetensi ditetapkan berdasarkan kebutuhan medis suatu penyakit dan kompetensi fasilitas pelayanan kesehatan (Rumah Sakit), bukan jenjang kelas rumah sakit. Sistem ini membutuhkan kemampuan 
Dinas kesehatan Provinsi untuk menyusun peta kompetensi dan sistem rujukan yang akan dibangun. Setiap provinsi akan mempunyai peta yang berbeda-beda.

Angka kematian ibu (AKI) di Indonesia masih tinggi yaitu 305 per 100.000 kelahiran hidup (BPS et al., 2016). Angka ini masih jauh dari target Sustainable Development Goals (SDGs) Indonesia yaitu 70 per 100.000 kelahiran hidup (BPS, 2016). Konsep "Three Delays" penyebab kematian ibu yaitu keterlambatan memutuskan mencari pelayanan, keterlambatan mencapai fasilitas kesehatan yang memadai, dan keterlambatan menerima pelayanan yang memadai di fasilitas kesehatan. Beban keuangan ditengarai dapat menghambat ibu dalam mendapatkan pelayanan persalinan di semua tipe keterlambatan. Salah satu upaya pemerintah untuk menekan tingginya Angka Kematian Ibu (AKI) adalah dengan menerapkan program Jaminan Kesehatan Nasional (JKN). Sistem Jaminan Sosial Nasional adalah sebuah sistem jaminan sosial yang ditetapkan di Indonesia dalam UU No. 40 Tahun 2004. Jaminan sosial ini adalah salah satu bentuk perlindungan sosial yang diselenggarakan oleh negara guna menjamin warga negaranya untuk memenuhi kebutuhan hidup dasar yang layak. Undang-Undang No.40 Tahun 2004 tentang Sistem Jaminan Sosial Nasional (SJSN) ini mengamanatkan bahwa jaminan sosial wajib bagi seluruh penduduk di Indonesia, termasuk Jaminan Kesehatan Nasional (JKN) melalui suatu Badan Penyelenggara Jaminan Sosial (BPJS). (Yulvira Media, 2019). Badan Penyelenggara Jaminan Sosial (BPJS) Kesehatan adalah badan hukum yang dibentuk untuk menyelenggarakan program jaminan kesehatan dengan tujuan untuk memproteksi seluruh masyarakat dengan premi terjangkau dan dengan coverage lebih luas untuk seluruh masyarakat (Abidin, 2016).

Rujukan adalah penyerahan tanggung jawab dari satu pelayanan kesehatan ke pelayanan kesehatan yang lain. Sistem rujukan adalah suatu jaringan pelayanan kesehatan yang memungkinkan terjadinya penyerahan tanggung jawab secara timbal balik atas timbulnya masalah dari suatu kasus atau masalah kesehatan masyarakat baik secara vertikal maupun horisontal kepada yang lebih kompeten, terjangkau dan dilakukan secara rasional. Sistem rujukan diselenggarakan dengan tujuan memberikan pelayanan kesehatan secara bermutu, sehingga tujuan pelayanan tercapai tanpa harus menggunakan biaya yang mahal. Rujukan merupakan suatu sistem dimana koordinasi merupakan unsur utama yang bersifat multi sektor dan harus ada dukungan dari berbagai profesi bersifat multi disiplin dan multi profesi untuk melaksanakan dan menyelenggarakan suatu bentuk layanan terpadu bagi penderita gawat darurat baik dalam keadaan sehari-hari maupun dalam keadaan bencana dan kejadian luar biasa. Rujukan yang efektif memerlukan komunikasi antar fasilitas, tujuannya agar pihak fasilitas terujuk mengetahui keadaan pasien dan dapat menyiapkan secara dini peannganan yang diperlukan pasien segera setelah pasien sampai dirumah sakit (Ratnasari, D. 2017).

Tujuan rujukan adalah dihasilkannya pemerataan upaya kesehatan dalam rangka penyelesaian masalah kesehatan secara berdaya dan berhasil guna. Tujuan Sistem rujukan adalah untuk meningkatkan mutu, cakupan dan efisiensi pelayanan kesehatan secara terpadu. Dengan memperkuat sistem rujukan tersebut merupakan salah satu cara untuk mempercepat penurunan Angka Kematian Ibu (AKI) serta dengan adanya problem dan tantangan puskesmas dalam mendukung system rujukan maternal ke Rumah Sakit Umum Daerah dapat diatasi. Rujukan harus mendapatkan persetujuan dari pasien dan atau keluarganya, serta tenaga kesehatan yang berwenang harus memberikan penjelasan kepada pasien mengenai diagnosis dan terapi atau tindakan medis yang diperlukan oleh pasien, alasan dan tujuan dilakukan rujukan, risiko yang dapat timbul apabila rujukan tidak dilakukan, transportasi rujukan, dan risiko atau penyulit yang dapat timbul selama perjalanan Pasal 12 Kemenkes RI 2012 (Kemenkes RI, 2012).

Sistem rujukan upaya keselamatan adalah suatu sistem jaringan fasilitas pelayanan kesehatan yang memungkinkan terjadinya penyerahan tanggung jawab secara timbal balik atas masalah yang timbul baik secara vertikal (komunikasi antara unit sederajat) maupun horisiotal (komunikasi inti yang lebih tinggi ke unit yang lebih rendah) ke fasilitas pelayanan yang lebih kompeten, terjangkau rasional, dan tidak dibatasi oleh wilayah administrasi. Sistem rujukan menurut Sistem Kesehatan Nasional Depkes RI 2009 
merupakan suatu sistem penyelenggaraan pelayanan kesehatan yang melaksanakan pelimpahan tanggung jawab timbal balik terhadap satu/lebih kasus penyakit atau masalah kesehatan secara vertikal dari unit berkemampuan kurang kepada unit yang lebih mampu atau secara horizontal antar unit - unit yang setingkat kemampuannya dalam bidang kesehatan maternal dan perinatal.

Sistem rujukan pelayanan kesehatan merupakan salah satu upaya dalam rangka meningkatkan mutu pelayanan kesehatan yang memberikan dampak pada penurunan Angka Kematian Ibu (AKI) dan Angka Kematian Bayi (AKB) akibat keterlambatan dalam penanganan kegawatdaruratan. Untuk mewujudkan hal tersebut beberapa wilayah propinsi di Indonesia mulai tahun 2015 telah membuat kebijakan pemerintah daerah ada yang mencanangkan dengan membuat program unggulan untuk menurunkan Angka kematian ibu dan bayi yang disebut AKINO (Angka Kematian ibu Nol) telah dideklarasikan sebagai salah satu upaya untuk mencapai tujuan Program AKINO adalah memperkuat sistem rujukan kesehatan diberbagai jenjang pelayanan kesehatan. Walapun program tersebut sampai sekarang belum bisa sepenuhnya diwujudkan oleh karena itu dalam sistem rujukan selain mengupayakan cepat dan tepat juga sangat direkomendasikan untuk melakukan Rujukan Terencana. Rujukan terencana merupakan suatu rujukan yang dikembangkan secara sederhana, mudah dimengerti, dan dapat disiapkan atau direncanakan oleh ibu atau keluarga dalam mempersiapkan pelayanan kesehatan ibu dan anak. Rujukan terencana ini bertujuan untuk menurunkan angka atau mengurangi rujukan terlambat, mencegah komplikasi penyakit ibu dan anak, serta mempercepat penurunan angka kematian ibu dan anak. Persiapan penderita juga perlu diperhatikan dengan BAKSOKUDA yang meliputi B (Bidan), A (Alat) K (Keluarga), S (Surat), O (Obat), K (Kendaraan), U (Uang) dan DA (Darah) (Dinas Kesehatan Provinsi Nusa Tenggara Barat, 2011).

Oleh karena itu untuk mendukung hal tersebut seluruh sarana pelayanan kesehatan baik pemerintah maupun swasta agar melaksanakan prosedur rujukan kesehatan yang mengacu pada Petunjuk Teknis Sistem Rujukan Pelayanan Kesehatan. Setiap sarana pelayanan kesehatan di kabupaten/kota agar membuat pemetaan alur rujukan pelayanan kesehatan yang disesuaikan dengan tingkat kemampuan fasilitas kesehatan, keberadaan jaringan transportasi, dan keadaan geografis wilayah masing-masing.

\section{Metode}

Studi ini merupakan tinjauan literatur (Literatur Review) dan penelitian- penelitian yang mencoba menggali lebih banyak informasi guna mengetahui sistem rujukan yang terjadi di Indonesia baik dalam Kabupaten, Provinsi, Puskesmas dan Rumah Sakit. Diskusi dalam rujukan ini merupakan suatu sistem dimana kordinasi merupakan unsur utama yang bersifat multi sektor dan harus ada dukungan dari berbagai profesi multi disiplin dan multi profesi.

\section{Diskusi}

Dalam bidang kesehatan Maternal dan Perinatal, menurut (Zulhadi, 2012), rujukan terlambat yang tinggi merupakan salah satu permasalahan utama dari terjadinya kematian ibu dan bayi. Keterlambatan ini disebabkan berbagai permasalahan dasar pada aspek kesehatan maupun non kesehatan. Beberapa diantaranya meliputi permasalahan dari faktor geografis, sosial, maupun kemampuan pembiayaan. Menurut Sistem Kesehatan Nasional (SKN) 2009 sistem rujukan pelayanan kegawatdaruratan maternal dan neonatal mengacu pada prinsip utama kecepatan dan ketepatan tindakan, efisien, sesuai dengan kemampuan dan kewenangan bidan serta fasilitas pelayanan. Setiap kasus dengan kegawatdaruratan maternal dan neonatal yang datang ke Puskesmas PONED (Penaggulangan Obstetri Neonatal Essensial Dasar) harus langsung dikelola sesuai dengan prosedur tetap. Setelah dilakukan stabilisasi kondisi pasien (pemberian obat-obatan, pemasangan infus dan pemberian oksigen) kemudian ditentukan apakah pasien akan dikelola di tingkat puskesmas PONED atau ditunjuk ke Rumah Sakit PONEK (Penaggulangan Obstetri Neonatal Emergency Komprehensif) untuk mendapatkan pelayanan yang lebih sesuai dengan kegawatdaruratan dalam upaya penyelamatan jiwa ibu dan anak (Sulistyo, DH. 2011).

Dalam kenyataan di lapangan didapatkan masih ada beberapa faktor yang menjadi sebab terjadinya rujukan terlambat seperti terjadinya komplikasi persalinan kesulitan 
pengambilan keputusan (terkait aspek ekonomi biaya transportasi) aspek geografis juga ketersediaan sarana prasarana rumah sakit. Selain itu selama rujukan faktanya di lapangan, response time rujukan masih dirasakan lama oleh pasien untuk mendapatkan pelayanan. Lama waktu disebabkan kesiapsiagaan tim medis yang kadang masih kurang tanggap merespon pasien, ibu hamil tidak membawa buku KIA dan tidak melengkapi persyaratan administrasi, sopir ambulans sulit dihubungi, konfirmasi pemberian informasi dari RS rujukan dan lamanya proses pemindahan pasien dari ruang bersalin ke kamar perawatan (Tirtaningrum, AD, 2018). Hal ini juga sesuai pendapat (Indah Indriani, 2015) dalam penelitiannya tentang Pengaruh Proses Rujukan dan Komplikasi Terhadap Kematian Ibu Di RSUD Sidoarjo, menyatakan bahwa Hasil Analisis proses rujukan yang kurang baik $(\mathrm{OR}=3,551 ; 95 \%), \mathrm{CI}=1,258-10,27$; $\mathrm{p}=$ $0,17)$ dan ibu hamil yang mempunyai komplikasi (OR 147,429; $95 \%, \mathrm{CI}=17,105$ $1270,702 ; \mathrm{p}=0,000)$ berpengaruh terhadap kejadian kematian ibu. Proses rujukan dan komplikasi berpengaruh terhadap kematian ibu, oleh karena itu bidan perlu mengadakan health education bagi wanita usia produktif, meningkatkan peningkatan kualitas Antenatal Care (ANC) dan peningkatan kualitas rujukan, melakukan deteksi dan intervensi serta monitoring (follow up) sehingga ibu hamil resiko tinggi selalu terpantau.

Saat ini pada kenyatannya sistem rujukan yang sudah diatur oleh pemerintah dalam berbagai tingkatan belum dapat terlaksana secara baik karena terbentur dalam hal wilayah geografis, sarana dan prasarana yang ada di daerah tersebut. Penyediaan akses pelayanan kesehatan ibu dan anak yang berkualitas masih menjadi tantangan besar untuk itu pemerintah harus memiliki komitmen yang kuat untuk meningkatkan status kesehatan ibu dan anak. Menurut pendapat (Windi, 2017) dalam penelitian tentang Implementasi Sistem Rujukan Ibu Hamil dan Bersalin oleh Bidan Polindes di wilayah Kecamatan Dampit Malang. yang menyatakan beberapa faktor yang mempengaruhi sistem rujukan antara lain biaya, pasien, pengambilan keputusan rumah sakit yang dituju, transportasi, kompetensi bidan, status domisili pasien dan kepercayaan masyarakat. Hal ini sesuai dengan pendapat
(Nova, E.M, 2019) dalam penelitiannya tentang Peran Bidan dalam Pengembangan Manual Rujukan KIA pada ibu Hamil Resiko Tinggi Di Kabupaten Bantul (Analisis Kejadian Kehamilan Resiko Tinggi) menyatakan bidan merupakan care provider dan merupakan bagian dari sistem rujukan, bidan dapat bertindak sebagai gete keeper bagi ibu hamil yang memerlukan layanan lanjutan. Kemampuan bidan dalam melakukan deteksi dini kehamilan dan resiko tinggi adalah faktor pendukung dalam penurunan Angka Kematian Ibu (AKI).

Salah satu upaya yang dilakukan untuk mewujudkan program penurunan Angka Kematian Ibu dan Bayi adalah memperkuat sistem rujukan kesehatan diberbagai jenjang pelayanan kesehatan. Khusus untuk kasus ibu hamil, regulasi sistem rujukan harus segera diterapkan, karena aturan yang diterapkan oleh BPJS mengharuskan persalinan normal dilakukan di faskes primer, padahal ibu-ibu dengan resiko tinggi harus melahirkan di rumah sakit, meskipun pada akhirnya mereka melahirkan normal, tetapi perdarahan dan komplikasi lain dapat terjadi sewaktu-waktu dan hal tersebut hanya dapat ditangani di rumah sakit PONEK. Hal ini yang ingin diselesaikan dengan regulasi manual rujukan. Prinsip utama adalah mengurangi kepanikan dan kegaduhan yang tidak perlu dengan cara menyiapkan persalinan (rujukan terencana) bagi yang membutuhkan (pre-emptive strategy). Meski sudah terdapat prinsip dan aturan terkait sistem rujukan, pada pelaksanaannya masih banyak hal-hal lain yang mempengaruhi keberhasilan dan kelancaran suatu rujukan seperti 3 terlambat. Agar sistem rujukan yang efektif dan efisien bisa tercapai perlu dilakukan beberapa intervensi antara lain membuat alat pemantauan kinerja rujukan berupa panduan/checklist yang digunakan sebagai pedoman alur perujukan yang baku sekaligus memudahkan pemerintah/instansi terkait untuk melakukan evaluasi kesesuaian sistem rujukan yang dilakukan. Selain itu diperlukan juga adanya perjanjian kerjasama jejaring rujukan. Dengan adanya sistem rujukan yang sudah diberlakukan hendaknya pemerintah mengupayakan fasilitas pendukung dan kebutuhan yang benar-benar terpenuhi dalam setiap lapisan daerah baik tingkat kabupaten, kota dan provinsi (Djunawan, A. 2018) 
Sejak tahun 2000, Kementerian Kesehatan Republik Indonesia telah mengembangkan konsep Sistem Penggulangan Gawat Darurat Terpadu (SPGDT) memasukkan penanganan gawat darurat mulai dari tingkat pra rumah sakit sampai tingkat rumah sakit dan rujukan antara rumah sakit dengan pendekatan lintas program dan multi sektoral. Penaggulangan gawat darurat menekankan respon cepat dan tepat dengan prinsip Time Saving is Life and Linb Saving. Didalam memberikan pelayanan medis Sistem Penggulangan Gawat Darurat Terpadu (SPGDT) dibagi menjadi 3 sub sistem yaitu sistem pelayanan pra rumah sakit, sistem pelayanan di rumah sakit dan sistem pelayanan antar rumah sakit. Ketiga sistem ini tidak dapat dipisahkan satu sama lain dan bersifat saling terkait dalam pelaksanaan sistem. Prinsip Sistem Penggulangan Gawat Darurat Terpadu (SPGDT) adalah memberikan pelayanan yang cepat, cermat dan tepat, dimana tujuannya adalah untuk menyelamatkan jiwa dan mencegah kecacatan (time saving is life and limb saving) terutama ini dilakukan sebelum dirujuk ke rumah sakit yang dituju (Mutamakin A. 2014)

Menurut pendapat (Dinda Nestelita, 2019) dalam penelitiannya tentang Proses Sistem Rujukan dalam Pelayanan Kegawatdaruratan Obstetri dan Neonatal di Puskesmas Sayung 2 Kabupaten Demak menyatakan, kelancaran rujukan dapat menjadi faktor yang menentukan untuk menurunkan AKI terutama dalam mengatasi keterlambatan. Salah satu pusat rujukan Puskesmas Sayung 2 yaitu RSJD Dr. Amino Gondohutomo, menyatakan bahwa terdapat beberapa kendala yang dihadapi dalam sistem rujukan antara lain keterbatasan petugas yang terlatih dan double job, kurangnya pemahaman petugas terhadap SOP, kesalahan komunikasi antar petugas kesehatan dan sistem informasi rujukan antara puskesmas dan rumah sakit yang kurang maksimal sehingga masih susah dalam mencari rumah sakit rujukan. Oleh karena itu hambatan yang ada yaitu Komponen proses dalam pelaksanaan sistem rujukan yang masih terdapat beberapa kendala dan perlu dibenahi yaitu sosialisasi SOP, kerjasama antara puskesmas dan rumah sakit lebih ditingkatkan, pengaktifan sistem informasi rujukan secara online agar lebih efektif.
Terkait pengaktifan sistem informasi rujukan online menurut pendapat (Lamtiur, J.B, 2019) dalam Penelitian Tentang Gambaran Sistem Rujukan (SISRUTE) Di RSUD Dr. RM Bolham Binjai 2019, menyatakan pemerintah telah mengeluarkan Surat Dirjen Pelayanan Kesehatan pada tanggal 10 Desember 2018 tentang Permohonan Penggunaan Sistem Rujukan Terintegrasi (SISRUTE) kepada seluruh Dinkes kab/kota/provinsi. Sisrute mempunyai fungsi dalam membantu perumusan kebijakan strategis dan teknis dibidang kesehatan rujukan yang berkesinambungan dan mendukung penyelenggaraan pemerintahan daerah di bidang kesehatan.

Menurut pendapat (Rukmini, 2018) dalam penelitiannya tentang Pelaksanaan Sistem Rujukan Maternal di Puskesmas Tambakrejo dan Tali Kedinding Kota Surabaya, menyatakan dalam upaya menurunkan angka kematian ibu diperlukan sistem rujukan yang efektif terutama untuk kasus komplikasi. Salah satu aspek fundamental dalam pelayanan kesehatan primer adalah adanya hubungan yang erat dengan level di atasnya, yang tercermin sebagai suatu sistem rujukan yang efektif. Pelaksanaan rujukan maternal meliputi prosedur klinis dan administrasi. Prosedur klinis yang telah dilaksanakan masih ada beberapa prosedur administrasi yang belum terlaksana yaitu pencatatan di buku register penerimaan rujukan pasien, pemberian surat balasan rujukan kepada fasilitas atau petugas kesehatan yang merujuk, prosedur standar menerima rujukan balik belum terlaksana. Koordinasi rujukan maternal antar fasilitas kesehatan telah terlaksana, dengan beberapa keterbatasan. Pelaksanaan rujukan maternal sudah sesuai dengan indikasi medis dan penanganan kasus persalinan sesuai dengan kewenangan puskesmas, oleh karena itu beberapa keterbatasan yaitu belum terlaksananya rujukan balik dari rumah sakit ke puskesmas, khususnya prosedur administrasi. dan karenanya untuk mengimplementasikan kebijakan rujukan balik, maka diperlukan rumah sakit perlu membuat prosedur standar secara tertulis untuk pengembalian rujukan. Demikian pula puskesmas perlu membuat prosedur standar penerimaan rujukan balik dari RS dan prosedur standar pengembalian rujukan ke puskesmas. 
Kenyataanya di lapangan dalam sistem rujukan perlu memperhatikan pula sistem rujuk balik di dalam sistem rujukan berbasis kompetensi. Dalam hal ini harus ada sistem yang menjadi acuan. Di sisi lain, sistem rujukan mestinya diserahkan kepada daerah karena setiap daerah memiliki kondisi yang berbeda. Rujukan yang dirasa paling penting adalah rujukan emergency, mengingat bahwa rujukan ini belum berjalan dengan optimal. Rujukan emergency misal untuk PONEK perlu diperkuat dan disertifikasi, oleh karena itu berbagai peraturan terkait rujukan perlu sinkronisasi dengan PMK Nomor 3 Tahun 2020, dibutuhkan peran Dinas Kesehatan untuk melakukan pemetaan kompetensi dan membuat standar disesuaikan dengan kondisi wilayah, sistem rujuk balik perlu ditata yang dapat dimulai dari layanan emergency, serta perlu adanya analisis terkait tarif dan sistem rujukan. Oleh karena itu dalam sistem rujukan alur pelayanan rujukan kegawatdaruratan Obstetri dan neonatal yaitu Puskesmas non PONED harus mampu melakukan stabilisasi pasien dengan kegawatdaruratan obstetri dan neonatal sebelum melakukan rujukan selanjutnya, puskemas PONED juga harus mampu memberikan pelayanan langsung terhadap ibu hamil/ibu bersalin dan ibu nifas dengan komplikasi tertentu sesuai dengan tingkat kewenangan dan kemampuan nya atau melakukan rujukan pada rumah sakit PONEK. Selain itu alur pelayanan rujukan kegawatdaruratan Obstetri dan neonatal rumah sakit PONEK 24 jam juga harus mempu memberikan pelayanan PONEK langsung terhadap ibu hamil/ibu bersalin dan ibu Nifas baik yang datang sendiri atau atas rujukan. Pemerintah provinsi/kabupaten dapat memberikan dukungan secara manajemen, administratif maupun kebijakan anggaran terhadap kelancaran pelayanan kegawatdaruratan obstetrik dan neonatal. Di Indonesia adanya alur pelayanan rujukan kegawatdaruratan obstetri dan neonatal Pokja/Satgas GSI (Gerakan Sayang Ibu) merupakan bentuk nyata kerjasama lintas sektoral di tingkat provinsi dan kabupaten untuk menyampaikan pesan peningkatan kewaspadaan masyarakat terhadap komplikasi kehamilan dan persalinan serta kegawatdaruratan yang mungkin terjadi (Sulistyo DH. 2011).
Dalam penangulangan permasalahan rujukan dalam merujuk kasus gawat darurat perlu diperhatikan stabilisasi penderita dengan pemberian oksigen, cairan infus intra vena, tranfusi darah serta obat-obatan. Stabilisasi kondisi pasien dan merujuknya dengan cepat dan tepat sangat penting (essensial) dalam menyelamatkan kasus gawatdarurat, tidak peduli jenjang atau tingkat pelayanan kesehatan. Tata cara untuk memperoleh transportasi dengan cepat bagi kasus gawat darurat harus ada pada setiap tingkat pelayanan kesehatan, sehingga dibutuhkan koordinasi dengan semua komponen. Dalam rujukan pasien harus didampingi oleh tenaga yang terlatih (dokter, bidan atau perawat sehingga cairan infus intravena dan oksigen dapat terus diberikan. Apabila pasien tidak didampingi oleh tenaga kesehatan, maka pendamping harus diberi petunjuk bagaimana menangani cairan intravena dalam perjalanan rujukan (Faulina, C,A, 2016)

Permasalahan lain yang cukup mengganggu di era JKN ini juga adanya beberapa aturan yang memberatkan dan adanya beberapa multitafsir antara BPJS dan pelaksana kesehatan terhadap aturan yang ada. Salah satu contoh di layanan primer adalah layanan ANC yang harus paling sedikit 4 kali kunjungan baru akan dibayar. Perlu dipahami bersama, dari sisi pelayanan kesehatan, upaya yang dilakukan dan sumber daya yang diperlukan terhadap persiapan keselamatan bayi pada persalinan SC tidak dapat disamakan dengan persalinan normal pada kasus fisiologis di layanan primer. Tentunya hal ini sangat memberatkan rumah sakit. Masih banyak kondisi pelayanan maternal lainnya yang bermasalah di era JKN ini seperti pelayanan keluarga berencana yang menjadi pilar pertama safemotherhood, mispersepsi definsi persalinan normal yang sering disamakan dengan persalinan pervaginal dan beberapa permasalahan lainnya (Rahmah H, 2019).

Memang dalam kondisi defisit keuangan BPJS yang semakin tahun semakin tinggi, beberapa upaya dilakukan untuk mengurangi pembiayaan kesehatan dengan melakukan verifikasi klaim secara ketat menjadi salah satu usaha membatasi pengeluaran dari pandangan payer. Namun dari sisi pelaksana pelayanan kesehatan, beberapa pengaturan layanan kesehatan dapat berdampak pada 
kualitas pelayanan yang bisa membahayakan kesehatan masyarakat itu sendiri.

Dengan adanya permasalahan tersebut perbaikan sistem pelayanan kesehatan maternal dan neonatal tidak cukup dengan hanya melakukan standarisasi pelayanan dan peningkatan kemapuan sumber daya manusia, tetapi juga perbaikan sistem rujukan maternal dan neonatal yang akan menjadi bagian dari tulang punggung sistem pelayanan secara keseluruhan Oleh karena itu penyelesaian permasalahan perlu diupayakan dari berbagai sisi, dengan harapan menunjang upaya penurunan angka kematian ibu yang masih sangat tinggi dibandingkan negara lain di kawasan Asia Tenggara.

Dengan adanya PMK Nomor 3 Tahun 2020 dimana rumah sakit akan semakin terbuka menangani kompetensi, PMK Nomor 3 Tahun 2020 sudah memulai mengarah pada basis kompetensi sehingga pasien tidak merasa terombang-ambing ketika mendapatkan layanan rujukan. Dari sisi lain PMK Nomor 3 Tahun 2020 perlu diharmonisasikan dengan peraturan-peraturan lain dan membutuhkan komitmen bersama. PMK tersebut perlu didukung dengan akses dan kualitas yang baik, dimana rumah sakit harus kompeten dari sisi layanan, SDM, dan sarana prasarana. Keterlibatan dinas kesehatan juga diperlukan Sistem tetap perlu diatur di rumah sakit dan rumah sakit perlu beradaptasi terhadap perubahan serta tetap berpedoman pada SOP maupun clincal pathway. Selain itu, apabila tarif tunggal akan diterapkan harus diatur terlebih dulu agar tidak membebani rumah sakit. BPJS Kesehatan juga menganggap perlu adanya penyesuaian antara PMK Nomor 3 Tahun 2020 dengan regulasi lain yang ada. Menanggapi PMK Nomor 3 Tahun 2020 tersebut perlu adanya koordinasi untuk menetapkan pemetaan rujukan berjenjang dan penerbitan klasifikasi surat ijin operasional rumah sakit sesuai kompetensi. Dinas Kesehatan dan BPJS Kesehatan di wilayah perlu bekerja sama dalam pemetaan terkait kompetensi.

Seperti kita ketahui, pengguna layanan BPJS kesehatan terbilang sangat besar jumlahnya. Mengingat layanan yang dikeluarkan Pemerintah ini memang cukup mudah diakses masyarakat luas sebagai alternatif dari asuransi kesehatan, meskipun demikian, beragam prosedur dan ketentuan yang berlaku di dalamnya masih sering menjadi hal yang tidak diketahui masyarakat. Ada banyak kesalahan serta kurangnya pemahaman masyarakat mengenai hal tersebut. Kurangnya pemahaman inilah yang kemudian menimbulkan masalah, baik dalam proses pengurusan/prosedur yang wajib dilakukan maupun berbagai ketentuan yang memang diberlakukan pemerintah selaku penyelenggara layanan tersebut. Hal ini masih saja menjadi salah satu kendala yang terjadi di dalam penggunaan layanan BPJS Kesehatan. Sebenarnya, pemerintah telah berupaya dalam memberikan beragam informasi dan ketentuan terkait layanan BPJS Kesehatan. Salah satu hal yang sering kali dipertanyakan dalam layanan BPJS Kesehatan adalah mengenai penanganan terhadap ibu hamil, dimulai dari pada masa kehamilan, persalinan, hingga pasca melahirkan. Hal ini banyak ditanyakan karena sering kali terjadi pemahaman yang berbeda soal penanganan tersebut (Hazfiarni, A, Ernawaty. 2016)

Pada era Jaminan Kesehatan Nasional (JKN), seluruh rakyat Indonesia yang terdaftar melalui Badan Pengelola Jaminan Nasional (BPJS) Kesehatan berhak untuk mendapatkan pelayanan kesehatan. Hal ini merupakan upaya pemerintah Indonesia untuk memenuhi hak kesehatan tiap individu masyarakat Indonesia. Salah satu tujuan dalam penerapan Jaminan Kesehatan Nasional adalah untuk mendapatkan pelayanan kesehatan yang bermutu dengan biaya yang efisien sesuai amanah undang undang Sistem Jaminan Sosial Nasional (SJSN) No. 40/2004. Kewenangan dinas kesehatan dalam pengendalian biaya adalah dengan membuat regulasi pelayanan kesehatan yang diberikan kepada pasien efektif dan sesuai kebutuhan, salah satu bentuknya dengan optimalisasi peran dokter primer dengan menurunkan angka rujukan yang tidak perlu dari puskesmas. Belum efektifnya sistem rujukan di Indonesia, berdampak pada penumpukan pasien di fasilitas kesehatan lanjutan, sehingga terjadi pemanfaatan tenaga terampil dan peralatan canggih secara tidak tepat guna dan menurunnya kualitas pelayanan kesehatan (Primasari, LK. 2015).

Selain itu sistem rujukan yang sudah diatur oleh pemerintah dalam berbagai tingkatan belum dapat terlaksana secara baik karena terbentur dalam hal wilayah geografis, sarana dan prasarana yang ada di daerah 
tersebut. Penyediaan akses pelayanan kesehatan ibu dan anak yang berkualitas masih menjadi tantangan besar untuk itu pemerintah harus memiliki komitmen yang kuat untuk meningkatkan status kesehatan ibu dan anak. Untuk mewujudkan ini program program penurunan angka ka kematian ibu dan bayi memperkuat sistem rujukan kesehatan diberbagai jenjang pelayanan kesehatan (Ignasius Luti MH, 2012) Oleh karena itu dengan adanya sistem rujukan yang sudah diberlakukan hendaknya Pemerintah mengupayakan fasilitas pendukung dan kebutuhan yang benar- benar terpenuhi dalam setiap lapisan daerah baik tingkat kabupaten, propinsi dan kota

Sistem rujukan kegawatdaruratan maternal dan neonatal mengacu pada prinsip utama kecepatan dan ketepatan tindakan, efisien, efektif dan sesuai kemampuan dan kewenangan fasilitas pelayanan. Sistem rujukan yang dibangun harus dilengkapi dengan manual supaya bisa dilaksanakan dengan lebih tertata dan jelas. Melalui anggaran APBN Program Kesga Tahun 2016, $\mathrm{kab} / \mathrm{kota}$ telah membentuk Pokja/Tim Manual dan menyusun manual rujukan maternal neonatal. Manual rujukan ini sebagai acuan dalam sistem rujukan dengan sumber pembiayaannya. Penyusunan manual tersebut diharapkan diperkuat dengan regulasi berupa Peraturan Bupati/Peraturan Walikota.

Dengan adanya PMK Nomor 3 Tahun 2020 terdapat beberapa harapan agar dapat diterapkan rujukan berbasis kompetensi dengan kriteria teknis yang ditetapkan oleh Kementrian Kesehatan dan di setiap provinsi akan ada peta rujukan layanan berbasis kompetensi. Pasca dikeluarkannya Permenkes Nomor 3 tahun 2020 tentang Klasifikasi dan Perizinan Rumah Sakit yang ditetapkan pada tanggal 14 Januari 2020 lalu, diharapkan ada perbaikan pada sistem kesehatan nasional dalam semua jenjang pelayanan kesehatan termasuk upaya penurunan angka kematian ibu dan bayi, harapannya penerapannya akan membawa perbaikan pelayanan kepada masyarakat, sekaligus memberi kenyamanan kepada seluruh tenaga medis dalam menjalankan tugasnya. Rumah sakit dapat memperluas SDM dan sarana prasarana, karena rujukan akan berdasarkan ketersediaan SDM dan kompetensi. Tidak ada lagi sistem rujukan berjenjang. Rumah sakit tipe apa saja bisa merujuk ke rumah sakit tipe apa saja, asalkan di rumah sakit tujuan bisa dan mampu menangani pasien tersebut.

\section{Kesimpulan}

Sistem rujukan yang sudah diatur oleh pemerintah dalam berbagai tingkatan belum dapat terlaksana secara baik karena terbentur dalam hal wilayah geografis, sarana dan prasarana yang ada di daerah tersebut. Penyediaan akses pelayanan kesehatan ibu dan anak yang berkualitas masih menjadi tantangan besar untuk itu pemerintah harus memiliki komitmen yang kuat untuk meningkatkan status kesehatan ibu dan anak. Untuk mewujudkan program Penurunan Angka Kematian Ibu (AKI) dan Angka Kematian Bayi (AKB) ini salah satu upaya untuk mencapai tujuan program tersebut adalah memperkuat sistem rujukan kesehatan diberbagai jenjang pelayanan kesehatan.

\section{Saran}

Dengan adanya sistem rujukan yang sudah diberlakukan hendaknya pemerintah mengupayakan fasilitas pendukung dan kebutuhan yang benar-benar terpenuhi dalam setiap lapisan daerah baik tingkat kabupaten, provinsi dan kota.

\section{Ucapan Terima Kasih}

Pada kesempatan ini penulis menyampaikan rasa terima kasih yang sebesar-besarnya kepada Lembaga Penelitian dan Pengabdian Kepada Masyarakat (LPPM) dan Komite Etik Sekolah Tinggi Ilmu Kesehatan Pamenang yang telah memberikan kami izin untuk melakukan literatur review serta memfasilitasi kebutuhan dalam artikel ilmiah ini.

\section{Daftar Pustaka}

Abidin. 2016. Pengaruh Kualitas Pelayanan BPJS Kesehatan Terhadap Kepuasan Pasien Di Puskesmas Cempae Kota Pare-Pare. Potekkes Maksar, Prodi Keperawatan Pare-pare. Jurnal MKMI, Volume 2, Juli 2016.

BPJS Kesehatan. Peraturan BPJS Nomor 8 Tahun 2016 Tentang Penerapan Kendali Mutu dan Kendali Biaya Pada Penyelenggaraan Program JKN. Jakarta : BPJS Kesehatan ; 2016.

Dinas Kesehatan Propinsi Nusa Tenggara Barat. Petunjuk Teknis Sistem Rujukan Pelayanan Kesehatan Propinsi Nusa Tenggara Barat. 2011 
Djunawan, A. 2018. Pengaruh Jaminan Kesehatan terhadap Pemanfaatan Pelayanan Kesehatan Primer di Perkotaan Indonesia: Adilkah bagi Masyarakat Miskin. Third UGM Public Health Symposium, Yogyakarta, 7 - 9 Mei 2018.

Dinda Nestelita, Antono Suryoputro, Wulan Kusumastuti. 2019. Proses Sistem Rujukan dalam Pelayanan Kegawatdaruratan Obstetri dan Neonatal Di Puskesmas Sayung 2 Kabupaten Demak. Fakultas Kesehatan Masyarakat Universitas Diponegoro. Medika Kesehatan Masyarakat Indonesia, 18 (4), 2019

Faulina, CA, Khoiri, A, Herawati, YK. 2016. Kajian Pelaksanaan Sistem Rujukan Berjenjang dalam Program Jaminan Kesehatan Nasional (JKN) di UPT. Pelayanan Kesehatan Universitas Jember. Jurnal IKESMA Volume 12 Nomor 2, September 2016.

Hazfiarni, A, Ernawaty. 2016. Indeks Kepuasan Pasien BPJS Kesehatan terhadap Pelayanan Rumah Sakit Mata di Jawa Timur. Jurnal Administrasi Kesehatan Indonesia, Volume 4, Nomor 2, Juli - Desember 2016.

Hardhantyo, M, Armiatin, Utarini, A, Djasri, H. 2016. Audit Mutu Layanan Rujukan Primer Guna Mengurangi Jumlah Rujukan ke Layanan Sekunder. Studi Kasus pada Provinsi DKI Jakarta. Jurnal Kebijakan Kesehatan Indonesia, Voluem 05, Nomor 04, Desember 2016

Hidayati, P, Hakimi, M, Claramita, M. 2017. Analisis Pelaksanaan Rujukan Berjenjang Fasilitas Kesehatan Tingkat Pertama Kasus Kegawatdaruratan Maternal Peserta Badan Penyelenggara Jaminan Sosial di 3 Puskesmas Perawatan Kota Bengkulu. Jurnal Kebijakan Kesehatan Indonesia, Volume 06, Nomor 02, Juni 2017

Ignasius Luti MH, Lutfan Lazuardi. 2012. Kebijakan Pemerintah Daerah dalam Meningkatkan Sistem Rujukan Kesehatan Daerah Kepulauan Di Kabupaten Lingga Kepulauan Riau. Jurnal Kebijakan Kesehatan Indonesia. 2012, Volume 01

Indah Indriani, Soenarnatalina Melaniani. 2015. Pengaruh Proses Rujukan dan Komplikasi Terhadap Kematian Ibu Di RSUD Sidoarjo. Jurnal Berkala Epidemiologi, Volume 3, Nomor 3, hal. 400 - 411, September 2015

Kemenkes RI. Pedoman Sistem Rujukan Nasional. Jakarta : Direktorat Jenderal Bina Upaya Kesehatan Kementerian Kesehatan RI ; 2012

Lamtiur J. Bancin, Nurul A.P, Nurul R, Ramsiska K, Rizki W.P. 2019. Gambaran Sistem Rujukan Terintegrasi (SISRUTE) di RSUD Dr. RM. Djoelham Binjai 2019. Program Studim D-IV manajemen Informatika
Kesehatan, Universitas Imelda Medan. Jurnal Ilmiah Perekan dan Informasi Kesehatan Imelda, Volume 5, Nomor 1 hal. 16 -19, ISSN 2502 7786, e-ISSn 2597 - 7156, Februari 2020.

Mutamakin A. 2014. Penerapan Sistem Informasi dalam Mendukung Sistem Rujukan di Fasilitas Kesehatan Tersier 2014

Maria Ery Setiawati, Rahmah Hida Nurrizka. 2019. Evaluasi Pelaksanaan Sistem rujukan Berjenjang dalam Program Jaminan Kesehatan Nasional. Fakultas Ilmu Kesehatan Universitas Pembeangunan Nasional Veteran Jakarta. Jurnal Kebijakan Kesehatan Indoonesia : JKKI, Volume 08, Nomor 1, hal 35 - 40, Maret 2019

Nova Elok Mardliyana, Nur Hidayah, A. 2019. Peran Bidan dalam Pengembangan Manual Rujukan KIA pada ibu Hamil Resiko Tinggi Di Kabupaten Bantul (Analisis Kejadian Kehamilan Resiko Tinggi). Fakultas Ilmu Kesehatan Universitas Muhammadiyah Surabaya. Jurnal Penelitian Kesehatan Suara Forikes, Volume 10, Nomor 1, ISSN 2086 3098, e- ISSN 2502 -77778, Januari 2019

Primasari, LK. 2015. Analisis Sistem Rujukan Jaminan Kesehatan Nasional RSUD. Dr. Adjimarno Kabupaten Lebak. Jurnal Administrasi Kebijakan Kesehatan Volume 1 Nomor 2, Januari 2015

Rukmini, 2015. Pelaksanaan Sistem Rujukan Maternal Di Puskesmas Takbakrejo dan Kali Kedinding Kota Surabaya. Buletin Penelitian Sistem Kesehatan, Volume 8, Nomor 4, hal. 365-375, Oktober 2015

Ratnasari, Dwi. 2017. Analisis Pelaksanaan Sistem Rujukan Berjenjang Bagi Peserta JKN di Puskesmas X Kota Surabaya. JAKI Volume 5, Nomor 2, Juli - Desember 2017.

Rahmah Hida Nurrizka, Marina Ery Setiawati,. 2019. Evaluasi Pelaksanaan Sistem Rujukan Berjenjang Dalam Program Jaminan Kesehatan Nasional. Fakultas Ilmu Kesehatan Universitas Pembangunan Veteran Jakarta. Jurnal Kebijakan Kesehatan Indonesia. JKKI, Volume 8, Nomor 01, Maret 2019

Sulistyo DH. 2011. Peran Program Sistem Hospital NTT Untuk Penguatan Sistem Rujukan Puskesmas PONED dengan Rumah Sakit PONEK. 2011

Sterie Yonara, Ratna Dri Wulandari. 2015. Penilaian Puskesmas dan Rumah Sakit Tentang Efektifitas Sistem Rujukan Maternal Di Kota Surabaya. Jurnal Administtrasi Kesehatan Indonesia, Volume 3, Nomor 2, Juli - Desember 2015

Tirtaningrum, AD, Sriatmi, A, Suryoputro, A. 2018. Analisis Response Time Penatalaksanaan Rujukan Kegawatdaruratan 
Obstetri Ibu Hamil. Jurnal MKMI, Vol. 14 No. 2, Juni 2018.

Windi, 2017. Implementasi Sistem Rujukan Ibu Hamil dan Bersalin oleh Bidan Polindes di wilayah Kecamatan Dampit Malang. Jurnal Informasi Kesehatan Indonesia, Volume 3, Nomor 1, hal. 71-84, Mei 2017

Yulvira, Media. 2019. Implementasi Program Jaminan Kesehatan Nasional dan Permasalahannya dalam Penurunan Angka Kematian Ibu (Studi di Kabupaten Solok Propinsi Sumatra Barat). Badan Ppenelitian dan Pengembangan Propinsi Sumatra Barat. 2019

Zulhadi LT, Siti Nur Zaenab. 2012. Problem dan Tantangan Puskesmas dan Rumah Sakit Umum Daerah dalam Mendukung Sistem Rujukan Maternal Di Kabupaten Karimun Propinsi Kepri. 2012, Volume2 